\title{
Surgical and functional outcomes after robot- assisted radical cystectomy in female patients: a systematic review of the literature
}

\author{
Paola Irene Ornaghi ${ }^{1}$, Alessandro Tafuri ${ }^{1}$, Rossella Orlando ${ }^{1}$, Andrea Panunzio ${ }^{1}$, Marco Moschini ${ }^{2}$, Luca \\ Afferi $^{2}$, Chiara Lonati ${ }^{2}$, Maria Angela Cerruto ${ }^{1}$, Alessandro Antonelli ${ }^{1}$ \\ 'Department of Urology, University of Verona, Azienda Ospedaliera Universitaria Integrata Verona, Piazzale Aristide Stefani, 1, \\ Verona 37126, Italy. \\ ${ }^{2}$ Department of Urology, Luzerner Kantonsspital, Spitalstrasse, Luzern 6004, Switzerland.
}

Correspondence to: Prof. Alessandro Antonelli, Department of Urology, University of Verona, Azienda Ospedaliera Universitaria Integrata of Verona, Confortini Surgical Center, Piazzale Aristide Stefani, 1, Verona 37126, Italy.

E-mail: alessandro.antonelli@aovr.veneto.it

How to cite this article: Ornaghi PI, Tafuri A, Orlando R, Panunzio A, Moschini M, Afferi L, Lonati C, Cerruto MA, Antonelli A. Surgical and functional outcomes after robot-assisted radical cystectomy in female patients: a systematic review of the literature. Mini-invasive Surg 2021;5:42. https://dx.doi.org/10.20517/2574-1225.2021.50

Received: 11 Apr 2020 First Decision: 21 May 2021 Revised: 14 Jun 2021 Accepted: 23 Jun 2021 First online: 2 Jul 2021

Academic Editors: Giulio Belli, Riccardo Autorino Copy Editor: Yue-Yue Zhang Production Editor: Yue-Yue Zhang

\begin{abstract}
Aim: We aimed to review and summarize recent data on surgical and functional outcomes in women undergoing robot-assisted radical cystectomy (RARC) and urinary diversion (UD) for bladder cancer, compared with male and open counterparts.
\end{abstract}

Methods: A systematic review of English-language articles published in the last 15 years was performed on PubMed/Medline database according to the Preferred Reporting Items for Systematic Reviews and Meta-Analyses statement. Outcomes of interest included peri- and post-operative surgical outcomes [operative time (OT), estimated blood loss (EBL), hospital stay (LOS), complications, and readmission], pathological outcomes [pT stage, lymph node (LN) yield, positive surgical margins (PSMs), and positive LN ( $\mathrm{pN}+$ )], and functional outcomes [daytime and nighttime continence, sexual activity, need for clean intermittent catheterization (CIC), and quality of life (QoL) evaluation].

Results: Overall, eight studies were selected collecting data from 229 female patients undergoing RARC. The median OT was $418 \mathrm{~min}$ (range 311-562 min) and the median EBL was $380 \mathrm{~mL}$ (range 100-1160 mL). OT and EBL were not significantly different comparing males and females, whereas the robotic approach was found to be 
significantly related with longer OT and lower EBL compared to the open procedure. The median LOS was 9.8 days (range 6.5-21 days); no significant differences in LOS were found between open RC (ORC) and RARC in female patients, as well as between RARC in women and men. The mean incidence of 30-day complications after RARC in women was $32.9 \%$, with $12 \%$ of high-grade complications, while the 30 - and 90 -day readmission rates were $20.8 \%$, and $28 \%$, respectively. Complications and readmission comparing RARC and ORC in female patients appear to be overlapping. The mean rate of PSMs was $2.5 \%$ and the mean rate of pN+ was $12.7 \%$; both these outcomes were similar in RARC compared with ORC. The mean number of retrieved LN was 20.6 (range 11.3-35.5). The LN yield resulted significantly influenced by the robotic approach [median 27 (range 19-41)] compared to the open one [20.5 (range 13-28)]. After 12 months, the rate of women with daytime and nighttime continence was $66.7 \%-90.9 \%$ and $66.7 \%-86.4 \%$, respectively, while that of sexually active women ranged $66.7 \%-72.7 \%$. The need for CIC ranged 12.5\%-27.2\%. Administering the EORTC-QLQ-C30 questionnaire after RARC and intracorporeal neobladder, the global health status/QoL and physical and emotional functioning items improved significantly over time.

Conclusion: RARC and UD in female patients is a feasible procedure with surgical outcomes overlapping with those in the male patient population. Postoperative functional outcomes on continence, sexual function, and QoL are still poorly investigated, although results inherent in the nerve-sparing approach appear promising.

Keywords: Bladder cancer, robot-assisted radical cystectomy, female, surgical outcomes, functional outcomes

\section{INTRODUCTION}

Bladder cancer $(\mathrm{BCa})$ is the second most common genitourinary malignancy, with 81,400 new cases and 17,980 deaths estimated in 2020 in the United States ${ }^{[1]}$. Although BCa is more frequent among men, among women there are approximately 20,000 new cases and about 5000 women die each year from this disease ${ }^{[1]}$.

Radical cystectomy (RC) with urinary diversion (UD) is considered the standard treatment for nonmetastatic muscle-invasive bladder cancer and high-risk non-muscle-invasive bladder cancer ${ }^{[2,3]}$. Women present an advanced stage at diagnosis more often, increasing the requirement of $\mathrm{RC}^{[4,5]}$. In female patients, the standard surgical procedure is represented by anterior pelvic exenteration including the removal of the bladder, ovaries, uterus, and anterior vaginal wall ${ }^{[2]}$. RC, whether open (ORC) or robot-assisted (RARC), is a morbid and complex procedure that involves simultaneous surgeries on the urinary and gastrointestinal tracts, as well as the retroperitoneum, with a substantial complication rate that may increase the length of hospital stay (LOS) and readmissions ${ }^{[6]}$. The robotic approach is increasingly performed worldwide ${ }^{[7]}$. Reportedly, progress in robotics has helped to develop standardized mini-invasive procedures which seem to offer oncological outcomes similar to open procedures and that are associated with reduced peri- and post-operative morbidity (decreased postoperative pain, incisional morbidity, blood loss, and transfusion rate) and shorter LOS, with an earlier return of bowel function ${ }^{[8-10]}$. After performing RARC, ileal conduit remains the most common type of reconstruction, even though an orthotopic neobladder (ONB) could offer a better quality of life (QoL) by maintaining body image and normal voiding in suitable patients ${ }^{[11]}$.

According to a recent review on gender-differentiated oncological and functional outcomes after RC, being a woman negatively affects oncologic outcome secondary to delays in diagnosis, treatment, and misdiagnosis. Moreover, functional outcomes (urinary, sexual, and overall QoL) are poorly assessed in women using non-validated and non-standardized measures ${ }^{[5]}$. Recent frontiers of improvement seem to be offered by totally intracorporeal reconstruction [intracorporeal urinary diversion (ICUD)] vs. extracorporeal UD (ECUD) ${ }^{[12]}$ and the nerve-sparing (NS)-RARC ${ }^{[13]}$. However, data on postoperative outcomes in female patients are still scarce and confusing, especially concerning the robotic approach. 
This systematic review aimed to comprehensively summarize the current evidence in the literature on surgical and functional outcomes after RARC in female patients, to identify the gaps and direct future investigations.

\section{METHODS}

\section{Literature search strategy and study selection}

A systematic review of the English-language literature published in the last 15 years (from 1 January 2005 to 31 December 2020) was performed. The US National Institutes of Health's PubMed Database was carefully scrutinized according to the Preferred Reporting Items for Systematic reviews and Meta-Analyses (PRISMA) statement ${ }^{[14]}$. The research was performed using the following search string: [radical cystectomy AND robot AND female AND (surgical outcome OR functional outcome)]. According to the aim of this study, all eligible texts reporting the peri- and post-operative outcomes under examination in female patients treated with RARC for BCa were included in the systematic review. After a first screening based on study title and abstract, all articles were examined based on full-text and excluded with reasons when inappropriate. The following types of articles were excluded from the systematic review: review articles, case reports, editorial/author replies or comments to other articles, studies reporting data without gender differentiation, studies from the same database with potential overlapping patients, and studies that dealt with research unrelated to our topic.

\section{Outcomes of interest}

Our primary outcomes were peri- and post-operative surgical outcomes [operative time (OT), estimated blood loss (EBL), LOS, 30- and 90-day complication rates according to Clavien-Dindo Classification System $(\mathrm{CCS})^{[15]}$, and 30- and 90-day readmission rates] and postoperative functional outcome [daytime and nighttime continence, sexual activity, need for clean intermittent catheterization (CIC), and health-related QoL (HRQoL) evaluation]. As secondary endpoints, we considered postoperative pathological outcomes [pT stage, lymph node (LN) yield, positive surgical margins (PSMs), and positive LN (pN+)].

\section{RESULTS}

\section{Evidence synthesis}

Figure 1 reports the flow diagram of the selection process used for this systematic review. From a total of 296 articles screened, 17 were initially assessed for eligibility. Of these, 9 were subsequently excluded after full-text evaluation and eight were selected and critically analyzed by the authors.

\section{Study population and design}

Overall, our systematic review included 514 patients (438 considering RARC only). Regarding the articles which included both male and female patients, given the topic of our systematic review, we focused particularly on female patients, in total 305 (229 considering RARC only). The characteristics of the eight identified studies together with the peri- and post-operative outcomes achieved are reported in Table 1.

Eligible articles were published between 2009 and 2020 involving female patients who underwent RARC from December 2003 to June 2018. All selected studies had a retrospective design; only one was a multicenter study ${ }^{[16]}$, whereas all others were based on data collected in a single institution. Four of the eight studies were from the USA ${ }^{[17-20]}$, one from Turkey ${ }^{[21]}$, one from Sweden ${ }^{[22]}$, one from Italy ${ }^{[13]}$, and one from Korea $^{[16]}$. Three of them were comparative articles: two reported gender comparison data ${ }^{[16,19]}$ and one compared RARC and ORC ${ }^{[18]}$. 
Table 1. Overview of the studies investigating surgical and functional outcomes in female patients with bladder cancer treated with robot-assisted radical cystectomy, grouped by endpoints of interest

\begin{tabular}{|c|c|c|c|c|c|c|c|c|}
\hline $\begin{array}{l}\text { Author, } \\
\text { year }\end{array}$ & Study design & Study size & $\begin{array}{l}\text { Type of } \\
\text { surgery }\end{array}$ & Follow-up & $\begin{array}{l}\text { Type of } \\
\text { urinary } \\
\text { diversion }\end{array}$ & $\begin{array}{l}\text { Preoperative } \\
\text { variables }\end{array}$ & $\begin{array}{l}\text { Peri- and Post- } \\
\text { operative outcomes }\end{array}$ & Findings \\
\hline $\begin{array}{l}\text { Tuderti et al. }{ }^{[13]}, \\
2020\end{array}$ & $\begin{array}{l}\text { Retrospective } \\
\text { (monocentric } \\
\text { study) }\end{array}$ & 11 & SS-RARC & $\begin{array}{l}\text { Median of } \\
28 \text { months } \\
\text { (IQR 14-51) }\end{array}$ & iN & $\begin{array}{l}\text { Age, BMI, gender, ASA } \\
\text { score, preoperative } \\
\text { eGFR, preoperative } \mathrm{Hb} \text {, } \\
\text { NAC rate }\end{array}$ & $\begin{array}{l}\text { - Surgical: OT, Hb at } \\
\text { discharge, LOS, } \\
\text { complications according to } \\
\text { CCS; } \\
\text { - Pathological: pT stage, } \\
\text { pN stage, histology, LN } \\
\text { yield, PSMs; } \\
\text { - Oncological: 1-year RFS, } \\
\text { 1-year CSS, 1-year OS; } \\
\text { - Functional: last eGFR, } \\
\text { ONB stones, UES, need for } \\
\text { CIC; daytime and } \\
\text { nighttime continence, } \\
\text { recovery probabilities; } \\
\text { EORTC QLQ-C3O and } \\
\text { EORTC QLQ-BLM30; FSFI } \\
\text { questionnaire }\end{array}$ & $\begin{array}{l}\text { Median OT was } 255 \text { min and the median LOS } 7 \\
\text { days. Low-grade CCS complications occurred in } \\
4 \text { patients ( } 36.3 \% \text { ), while high-grade CCS not } \\
\text { observed. } 7 \text { patients ( } 63.7 \% \text { ) had an organ- } \\
\text { confined disease at the pathologic specimen; } \\
\text { nodal involvement and PSMs not detected } \\
\text { No new onset of CKD stage } 3 b \text {. After one year, } \\
\text { daytime and nighttime continence rates were } \\
90.9 \% \text { and } 86.4 \% \text {, respectively. Three patients } \\
\text { (27,2\%) performed CIC twice a day } \\
\text { QoL as well as physical and emotional } \\
\text { functioning (EORTC QLQ-C30) improved } \\
\text { significantly over time (all P } P 0.04 \text { ), while } \\
\text { urinary symptoms (EORTC QLQ-BLM30) and } \\
\text { sexual function (FSFI) worsened at } 3 \text { months } \\
\text { with a significant recovery taking place at one } \\
\text { year (all P } P 0.04 \text { ) } \\
\text { Overall, } 8 \text { out of } 11 \text { patients ( } 72.7 \% \text { ) were } \\
\text { sexually active at the } 12 \text {-month evaluation }\end{array}$ \\
\hline $\begin{array}{l}\text { Narayan et al. }{ }^{[18]} \text {, } \\
2019\end{array}$ & $\begin{array}{l}\text { Retrospective } \\
\text { (monocentric } \\
\text { study) }\end{array}$ & 122 & $\begin{array}{l}\operatorname{ORC}(76), \text { RARC } \\
(46)\end{array}$ & NR & $\begin{array}{l}\text { ICUD (40/46 } \\
\text { RARC); ECUD }\end{array}$ & $\begin{array}{l}\text { Age, race, BMI, } \\
\text { smoking, NAC, ASA } \\
\text { score, CCI, prior pelvic } \\
\text { surgery, preoperative } \\
\text { TNM }\end{array}$ & $\begin{array}{l}\text { - Surgical: OT; EBL, IT, PT, } \\
\text { ICU, LOS, 30- and } 90 \text {-day } \\
\text { complication rates } \\
\text { according to CCS, 30- and } \\
\text { 90-day readmission rates; } \\
\text { - Pathological: pT stage, } \\
\text { pN stage, pM stage, LVI, } \\
\text { LN yield, PSMs }\end{array}$ & 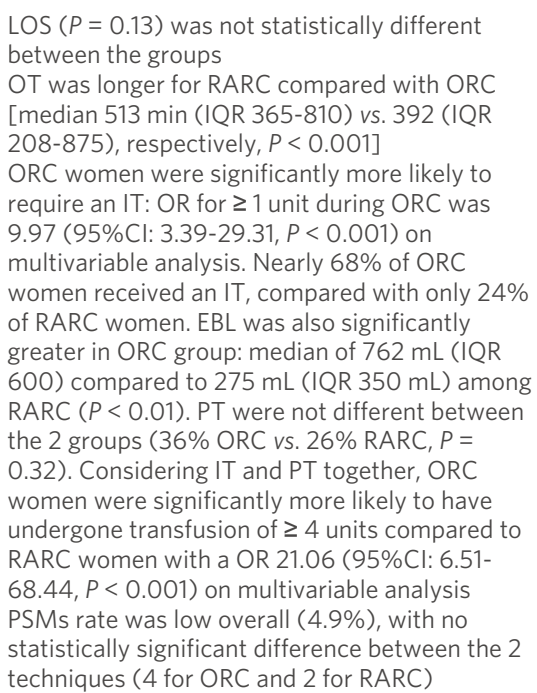 \\
\hline
\end{tabular}




\begin{tabular}{|c|c|c|c|c|c|c|}
\hline $\begin{array}{l}\text { Whittum et al. }{ }^{[17]} \text {, } \\
2018\end{array}$ & $\begin{array}{l}\text { Retrospective } \\
\text { (monocentric } \\
\text { study) }\end{array}$ & 118 & RARC & $\begin{array}{l}\text { Median of } 9 \\
\text { months (IQR } \\
6-13 \text { ) for } \\
\text { organ } \\
\text { invasion; } 23 \\
\text { months (IQR } \\
\text { 8-45) for no } \\
\text { organ } \\
\text { invasion }\end{array}$ & $\begin{array}{l}\text { IC (106); others } \\
\text { (12) }\end{array}$ & $\begin{array}{l}\text { Age, BMI, ASA score, } \\
\text { NAC, prior } \\
\text { abdominal/pelvic } \\
\text { surgery, prior RT, LVI } \\
\text { at TURBT, tumor site } \\
\text { at TURBT, histology at } \\
\text { TURBT }\end{array}$ \\
\hline
\end{tabular}

Tyritzis et al. ${ }^{[22]}$ 2013

invasion

Age, sex, BMI, ASA score, preoperative
Retrospective (monocentric study)
70 (62 male, 8 emale)

$\begin{array}{ll}\text { RARC (nerve } & \text { Median of } \\ \text { sparing-RARC in } & 30.3 \text { months } \\ \text { all female) } & \text { (IQR 12.7- } \\ & \text { 35.6) }\end{array}$

LN yield was higher for RARC compared with ORC, with a median of 27 nodes (IQR 7-57) compared with 20.5 nodes (IQR 0-57) ( $P<$ 0.001). The overall rate of $\mathrm{N}+$ disease was low between both groups $(P=0.89)$

The overall complication rate was $75.4 \%$ with vs. $73.9 \%$, respectively, $P=0.83$ ) The majority of complications ( $89.5 \%$ vs. $82.3 \%$ ) were $<3$ CCS complications Overall 30 - and 90 -day readmission rates were $24 \%$ and $29.8 \%$, respectively, with no difference observed between ORC or RARC groups ( $P=$ 0.67 and $P=0.68)$

- Surgical: OT, type of UD, 17 patients (14\%) showed a gynecological organ EBL, ICU, LOS, 30- and 90- invasion at pathological specimen. These day complications, 30 - and patients had more LVI at TURBT ( $82 \%$ vs. $46 \%$, 90-day readmission $\quad P=0.006$ ), trigonal tumours at TURBT (59\% vs. Pathological: pT stage (gynecological organ invasion), pN stage, histology, PSMs;
- Oncological: AC; 30 - and 90-day OS $18 \%, P=0.001)$, multifocal disease $(65 \%$ vs. (24\% vs $4 \%, P=0.02)$, and they less comms (24\% vs $4 \%$; $=0.02)$ and they less com emonstrated pure urothelial carcinoma at There was no statistically significant difference between the two groups in terms of hospital or Cus, complications, readmissions, mortality at 30 and 90 days

On mulivariate analysis, significant predictors of gynecological organ invasion were $\mathrm{pN}$ positive disease (OR 6.48, $95 \%$ Cl. $1.64-25.51, P=$ 0.008 ), trigonal tumour location (OR $5.72,95 \%$ Cl: $1.39-23.61, P=0.02)$, and presence of varian histology (OR $18.52,95 \% \mathrm{Cl}: 3.32-103.4, P=$ 0.001) NM, preoperative grade, concon

Surgical: OT, type of

They recorded negative margins in 69 of 70

PLND, nerve sparing, EBL, patients (98.6\%). Clavien 3-5 complications

LOS, $\geq 30$-day/90-day occurred in $22 / 70$ patients (31.4\%) at 30 -day

complications according to and 13/70 (18.6\%) at > 30-day. At 90-day, the

CCS; $\quad$ overall complication rate was $58.5 \%$. Clavien $<3$

Pathological: pT stage, and Clavien $\geq 3$ complications were recorded in

CIS, $15 / 70$ patients $(21.4 \%)$ and $26 / 70$

$\begin{array}{ll}\text { PSMs, GS, LN yield; } & \text { respectively } \\ \text { - Oncological: } 24-m o n t h & \text { Kaplan-Meier estimates for RFS, CSS and OS at }\end{array}$ recurrence, recurrence location, RFS, CCS, OS; - Functional: 6/12-month daytime and nighttime 24 months were $80.7 \%, 88.9 \%$, and $88.9 \%$, respectively

Daytime and nighttime continence at 12 months
reaches $80 \%-90 \%$ in men and $70 \%$ women. At ( 12 months, 46 men (74.2\%) and 2 of 3 evaluable $6 / 12$-month potency and females $(66.7 \%)$ were continent. One female 


\begin{tabular}{|c|c|c|c|c|c|c|c|c|}
\hline & & & & & & & sexual activity & $\begin{array}{l}\text { patient had to perform CIC (12.5\%). } 26 \text { ( } 81.2 \%) \\
\text { of the nerve-spared patients were potent with or } \\
\text { without PDE5-I at } 12 \text { months. } 4 \text { of } 6 \text { evaluable } \\
\text { women ( } 66.7 \%) \text { remained sexually active } \\
\text { postoperatively. Preoperatively potent patients } \\
\text { remained sexually active after surgery. Age will } \\
\text { have a negative impact on outcomes in } \\
\text { preserving daytime continence and in achieving } \\
\text { successful sexual function }\end{array}$ \\
\hline $\begin{array}{l}\text { Kaufmann et al. }{ }^{[20]}, \\
2011\end{array}$ & $\begin{array}{l}\text { Retrospective } \\
\text { (monocentric } \\
\text { study) }\end{array}$ & 12 & RARC & $\begin{array}{l}\text { Median of } \\
9.0 \pm 6.0 \\
\text { months }\end{array}$ & $\begin{array}{l}\text { IC (10); ONB (1); } \\
\text { IP (1) }\end{array}$ & Age, BMI & $\begin{array}{l}\text { - Surgical: OT, type of UD, } \\
\text { EBL, TTF, LOS, } \\
\text { complications; } \\
\text { - Pathological: pT stage, } \\
\text { pN stage, LN yield, PSMs, } \\
\text { histology }\end{array}$ & $\begin{array}{l}\text { Median total OT was } 6.4 \pm 1.5 \mathrm{~h} \text {. Median EBL } \\
\text { was } 275.0 \pm 165.8 \mathrm{~mL} \text {. Median TTF was } 3.5 \pm 1.4 \\
\text { days. Median LOS was } 8.0 \pm 1.6 \text { days } \\
4 \text { patients were T2NO or less, } 5 \text { patients T3NO, } 1 \\
\text { patient T3N1 and } 2 \text { patients T } 4 \text { NO. There was } \\
\text { one PSM in a patient with stage PT } 4 \text { aNO } \\
\text { disease. Median LN yield removed was } 23 \pm 11.4 \\
1 \text { had a recurrent ureteroenteric stricture, } 1 \text { had } \\
\text { colpocleisis for vault prolapse, and } 3 \text { had } \\
\text { metastatic disease }\end{array}$ \\
\hline Canda et al. ${ }^{[21]}, 2011$ & $\begin{array}{l}\text { Retrospective } \\
\text { (monocentric } \\
\text { study) }\end{array}$ & $\begin{array}{l}27 \text { ( } 25 \text { male, } 2 \\
\text { female) }\end{array}$ & $\begin{array}{l}\text { Nerve sparing- } \\
\text { RARC }\end{array}$ & $\begin{array}{l}\text { Mean of } 6.3 \\
\text { months } \\
\text { (IQR 1.8- } \\
11.3 \text { ) }\end{array}$ & $\begin{array}{l}\text { IC (2); iN (2 } \\
\text { female/25) }\end{array}$ & $\begin{array}{l}\text { Age, sex, BMI, } \\
\text { preoperative IIEF } \\
\text { score, preoperative } \\
\text { TNM, CCI, ASA score, } \\
\text { prior abdominal } \\
\text { surgery, smoking, } \\
\text { mean creatinine level }\end{array}$ & $\begin{array}{l}\text { - Surgical: OT, type of } \\
\text { PLND, nerve sparing, EBL, } \\
\text { LOS, 30-day/90-day } \\
\text { complications according to } \\
\text { CCS, readmission; } \\
\text { - Pathological: pT stage, } \\
\text { pN stage, PSMs, GS, LN } \\
\text { yield; } \\
\text { - Functional: daytime } \\
\text { [none (0-1 pad/die), mild } \\
\text { (1-2 pads/die), moderate } \\
(3 \text { pads/die) and severe (> } \\
3 \text { pads/die)] and } \\
\text { nighttime [good (dry, no } \\
\text { protection), fair (dry, one } \\
\text { awakening) and poor (wet, } \\
\text { leakage and incontinence } \\
\text { during sleep)] continence, } \\
\text { postoperative IIEF }\end{array}$ & $\begin{array}{l}\text { The mean OT, EBL and LN yield were } 9.9 \text { (IQR } \\
\text { 7.1-12.4) h, 429 (IQR 100-1200) mL and } 24.8 \\
\text { (IQR 8-46), respectively. The mean LOS was } \\
10.5 \text { (IQR 7-36) days, there was one } \\
\text { perioperative death (3.7\%), surgical margins } \\
\text { were negative in all but one patient who had } \\
\text { pT 4b disease } \\
\text { Pathological stages: pTO (5), pTis (1), pT1 (1), } \\
\text { pT2a (5), pT2b (3), pT3a (6), pT3b (2), pT4a } \\
\text { (3) and pT4b (1). N + and incidental prostate } \\
\text { cancer were detected in } 6 \text { and } 9 \text { patients, } 3 \\
\text { patients died from metastatic disease and } 1 \text { from } \\
\text { cardiac disease } \\
\text { Complications: there were } 9 \text { minor and } 4 \text { major } \\
\text { 30-day complications; } 4 \text { minor and } 3 \text { major } 90- \\
\text { day complications ( } 31-90 \text { days) } \\
\text { Of the available } 18 \text { patients, } 11 \text { were fully } \\
\text { continent, four had mild and two had severe } \\
\text { daytime incontinence. Concerning two female } \\
\text { patients who underwent intracorporeal Studer } \\
\text { pouch, both currently have severe (> } 3 \\
\text { pads/die) daytime and poor (wet, leakage and } \\
\text { incontinence during sleep) nighttime urinary } \\
\text { incontinence. However, the postoperative } \\
\text { follow-up is very limited for these } 2 \text { patients ( } 6 \\
\text { and } 5 \text { months) }\end{array}$ \\
\hline Kang et al. ${ }^{[16]}, 2010$ & $\begin{array}{l}\text { Retrospective } \\
\text { (multicenter } \\
\text { study) }\end{array}$ & $\begin{array}{l}104 \text { ( } 82 \text { male, } 22 \\
\text { female) }\end{array}$ & RARC & $\begin{array}{l}\text { Mean of } 12 \\
\text { months (IQR } \\
3-24)\end{array}$ & $\begin{array}{l}\text { IC (13 } \\
\text { female/60); } \\
\text { ONB }(9\end{array}$ & $\begin{array}{l}\text { Age, sex, BMI, } \\
\text { preoperative TNM, } \\
\text { ASA score, }\end{array}$ & $\begin{array}{l}\text { - Surgical: OT, EBL, IT, type } \\
\text { of PLND, type of UD, TTF, } \\
\text { LOS, complications }\end{array}$ & $\begin{array}{l}\text { The mean total OT was } 554 \text { min ( } 567 \text { in female, } \\
550 \text { in male, } P=0.64 \text { ), and the mean EBL was } \\
526 \mathrm{~mL}(591 \text { in female, } 515 \text { in male, } P=0.32 \text { ) }\end{array}$ \\
\hline
\end{tabular}




$\begin{array}{lll}\text { Pruthi et al. }{ }^{[19]}, & \begin{array}{l}\text { Retrospective } \\ \text { (monocentric } \\ \text { study) }\end{array} & \begin{array}{l}50 \text { (40 male, } 10 \text { RARC } \\ \text { female }\end{array}\end{array}$

female/44)

$\begin{array}{ll} & \text { female/44) } \\ & \\ & \\ \text { Median of } 14 & \text { IC (7 } \\ \text { months (IQR } & \text { female/30); } \\ 0.2-73) & \text { ONB (3 } \\ & \text { female/20) }\end{array}$

according to CCS; - Pathological: pT stage, pN stage, PSMs, LN yield, histology:

- Oncological: DFS

Age, sex, BMI, preoperative TNM
- Surgical: OT, type of UD, EBL, TTF, LOS, 30-day complications; - Pathological: pT stage, $\mathrm{pN}$ stage, $\mathrm{PSMs}$, LN yield
The TTF and bowel movement was about 3 days $(P=0.38)$, and LOS was about 18 days ( 20 in female, 17.7 in male, $P=0.19$ )

The mean $L N$ yield removed were 18 (16.0 in female, 19.1 in male $P=0.32$ ) and 10 patients had node metastatic disease on fina patients had node metastatic disease on final patholog evaluation. Postoperative complications occurred in 28 (26.9\%) patients, major

complications in $20(19.2 \%)$ patients

Female patients had shorter OT ( $4.6 \mathrm{~h}$ vs. 5.9 $0.012)$ and approached a shorter time to bowe movement ( 2.4 days vs. 2.8 days, $P=0.057$ ).

Mean TTF was 1.9 days (vs. 2.2 days), and mean LOS was 4.9 days vs. 4.4 days). These outcomes were comparable to the male patients,

particularly the 20 male patients undergoing RARC during the same time period

On surgical pathology, 5 patients were $\leq \mathrm{pT} 2$ ( vs. 28) 3 patients pT3 (vs. 6) and 2 p p 12 ( (s 6). The 3 palients p 3 (vs. 6), and 2 patients $\mathrm{N}+$ (s 6). There were no PSMs. Mean number of LN removed was 19 (IQR 12-34), vs. 18 (IQR 8-37). Males were more often organ confined in our series $(70 \%$ vs. $50 \%$ ), but node-positive rates were not significantly different (15\% vs. 20\%) In female patients, 30-day complications included 2 complications in 2 patients. Complication rates in the male cohort was $30 \%$, but this was not found to be statistically different than the rate in females

RC: Radical cystectomy; RARC: robot-assisted radical cystectomy; SS-RARC: sex-sparing-robot-assisted radical cystectomy; ORC: open radical cystectomy; LRC: laparoscopic radical cystectomy; IQR: interquartile range; iN: intracorporeal neobladder; BMI: body mass index: ASA: American society of anesthesiologists: OT: operative time; Hb: hemoglobin: LOS: length of hospital stay; CCS: Clavien-Dindo classification system; AC: adjuvant chemotherapy; NAC: neoadjuvant chemotherapy; PSMs: positive surgical margins; UES: uretero-enteric strictures; CIC: clean intermittent catheterization; FSFI: female sexual function index; CKD: chronic kidney disease; QoL: quality of life; NR: not reported; UD: urinary diversion; ICUD: intracorporeal urinary diversion; ECUD: extracorporeal urinary diversion; CCI: Charlson comorbidity index; EBL: estimated blood loss; IT: intraoperative transfusion; PT: postoperative transfusion; OR: odds ratio; Cl: confidence interval; LN: lymph node; ONB: orthotopic neobladder; IC: ileal conduit; CCD: continent cutaneous diversion; IPC: Indiana pouch; RFS: recurrence-free survival; OS: overall survival: DFS: disease-free survival; UTI: urinary tract infection; RT: radiotherapy: ICU: intensive care unit: LVI: lymphovascular invasion; TURBT: transurethral resection of bladder tumour; TTF: time to flatus; OS: overall survival; CSS: cancer-specific survival; CIS: cancer in situ; GS: Gleason Score; PLND: pelvic lymph node dissection; IIEF: international index of erectile function; PDE5-I: phosphodiesterase type 5 inhibitors.

All articles collected dealt with female patients undergoing RARC. In three of these studies, the technique applied was NS ${ }^{[1,21,22]}$, specifically to safeguard functional postoperative outcomes. One article also included ORC, comparing the outcomes of the two approaches ${ }^{[18]}$. 
The female patients underwent different types of UD: most of them underwent ileal conduit (136 cases), while 34 underwent neobladder; in 13 cases, it was defined as ONB and in 21 cases it was defined as intracorporeal neobladder (iN). One patient underwent Indiana pouch, while in 58 cases the type of urinary reconstruction was not specified.

\section{Preoperative characteristics}

The mean age of the female patients was 61.12 years (range 48.25-71.25 years). The mean body mass index (BMI) recorded was $24.7 \mathrm{~kg} / \mathrm{m}^{2}$ (range $19.8-34 \mathrm{~kg} / \mathrm{m}^{2}$ ). Three of the studies also reported the preoperative ASA (American Society of Anesthesiologists) score ${ }^{[13,17,18]}$. In the study by Narayan et al. ${ }^{[18]}$, comparing RARC and ORC, the rate of patients with ASA $\geq 3$ was high and similar in RARC vs. ORC $(93.48 \% v s$. $92.11 \%, P=1$ ). In contrast, the study by Tuderti et al ${ }^{[13]}$, which focused on sex-sparing (SS)-RARC, enrolled patients with a low ASA score $(<3)$ in more than $90 \%$ of cases. Whittum et al. ${ }^{[17]}$ found that a higher percentage of patients with an ASA score $\geq 3$ was associated with gynecological organ invasion at RARC histology, although this did not reach statistical significance ( $76 \% v s .57 \%, P=0.14)$.

\section{Peri- and post-operative surgical outcomes}

The median OT of RARC in female patients was $418 \mathrm{~min}$ (range 311-562 min). The median EBL was 380 $\mathrm{mL}$ (range 100-1160 mL). Pruthi et al. ${ }^{[19]}$, when comparing female and male patients, reported that women had shorter OT (mean $276 \mathrm{~min} v s .354 \mathrm{~min}, P<0.001$ ) and less EBL (mean $215 \mathrm{~mL} v s .330 \mathrm{~mL}, P=0.012$ ). This difference was only significant, however, comparing female patients with a cohort of 20 male patients operated at the beginning of the learning curve, whereas no parameters were different between the female and the concurrent male patients. Kang et al. ${ }^{[16]}$ also compared perioperative outcomes between females and males. They obtained non-significant differences in OT (median $567 \mathrm{~min} v s .550 \mathrm{~min}, P=0.64$ ) and EBL (median $591 \mathrm{~mL} v s .515 \mathrm{~mL}, P=0.32$ ).

In the study by Narayan et al. ${ }^{[18]}$, OT was longer for RARC compared with ORC [median 513 (IQR 365-810) min vs. 392 (IQR 208-875) min, respectively, $P<0.001$ ], and the median EBL in RARC was significantly lower than in ORC [275 (IQR 150-700) mL vs. 762 (IQR 100-7000) mL, $P<0.01$ ]. Furthermore, women who underwent ORC were significantly more likely to require an IT. OR for the transfusion of $\geq 1$ unit during ORC was 9.97 (95\%CI: 3.39-29.31, $P<0.001$ ) on multivariable analysis: nearly $68 \%$ of women who underwent ORC received an IT, compared with only $24 \%$ of those that underwent RARC. EBL was also significantly greater in the ORC group: median of $762 \mathrm{~mL}$ (IQR $600 \mathrm{~mL}$ ) compared to $275 \mathrm{~mL}$ (IQR 350 $\mathrm{mL})$ in the RARC group $(P<0.01)$. Postoperative transfusion $(\mathrm{PT})$ did not differ between the two groups (36\% ORC vs. 26\% RARC, $P=0.32$ ). Considering IT and PT together, women who underwent ORC were significantly more likely to have undergone the transfusion of $\geq 4$ units compared to RARC with a OR 21.06 (95\%CI: 6.51-68.44, $P<0.001)$ on multivariable analysis.

The median LOS was 9.8 days (range 6.5-21 days) with a median time to flatus (TTF) of 3.5 days. Postoperative LOS did not seem to be significantly influenced by the type of surgical approach [ORC $v s$. RARC: median 6 (IQR 5-8) days vs. 5 (IQR 4-7) days, $P=0.13]^{[18]}$. No differences were found when comparing female to male RARC patients in the studies by both Pruthi et al ${ }^{[19]}$ (mean 4.9 days vs. 4.4 days, $P$ $>0.05$ ) and Kang et al. ${ }^{[16]}$ (median 20 days vs. 17.7 days, $P=0.19$ ).

All included studies reported the complication rate. The mean incidence of early postoperative complications (30-day complications) was $32.9 \%$, with a percentage of high-grade complications (CCS $\geq 3$ ) that tended to be low, averaging around $12 \%$. Narayan et al ${ }^{[18]}$ found no difference in rates of overall complications between ORC and RARC groups $(76.3 \%$ vs. $73.9 \%$, respectively, $P=0.83)$. Although the complication rate was higher in this study compared to the others, most of them (89.5\% for ORC and $82.3 \%$ 
for RARC) were < 3 CCS complications. Whittum et al. ${ }^{[17]}$ recorded complication rates within 30 and 90 days after surgery in their study, which were $49 \%$ and $61 \%$, respectively. Furthermore, when comparing patients with gynecological organ invasion at RC histology with those without, there was no significant difference between the two groups in the rate of postoperative complications (30-day: $47 \%$ vs. $51 \%, P=0.79$; 90-day: $59 \%$ vs. $62 \%, P=0.78)$.

In the studies collected in our research, the readmission rate after RARC in women was $20.8 \%$ in the first 30 postoperative days and $28 \%$ in the first 90 days. Narayan et al.$^{[18]}$ showed that these rates were overlapping with ORC (ORC vs. RARC, 30-day: $22.67 \%$ vs. $29.09 \%, P=0.67$; 90 -day: $28 \% v s .32 .61 \%, P=0.68$ ).

\section{Postoperative pathological outcomes}

The average detection rate of $\mathrm{pT} 3$ on histological examination of RARC was about $33 \%$, with similar rates compared to the open approach ${ }^{[18]}$.

Surgical margins were negative in close to $100 \%$ of operations (with a mean of $97.5 \%$ ). The robotic approach was similar to the open approach (PSMs $4.44 \%$ vs. $5.26 \%, P=1$ ) $^{[18]}$. The association between PSMs and gynecological organ invasion was significant $(24 \% \text { of cases } v s .4 \% \text { of cases without invasion, } P=0.02)^{[17]}$. In the multivariable analysis performed by Whittum et al.$^{[17]}$, the number of $\mathrm{pN}+(\mathrm{OR}=6.48,95 \% \mathrm{CI}$ : 1.64 $25.51, P=0.008)$, the trigonal tumor location $(\mathrm{OR}=5.72,95 \% \mathrm{CI}: 1.39-23.61, P=0.02)$, and the presence of variant histology other than pure urothelial ( $\mathrm{OR}=18.52,95 \% \mathrm{CI}$ : $3.32-103.4, P=0.001)$ were confirmed as predictors of gynecological organ invasion.

In the cohort of female patients undergoing RARC collected in our study, the mean $\mathrm{pN}+$ rate was $12.72 \%$. The difference with the rate of $\mathrm{pN}+$ found after ORC did not reach statistical significance $(P=0.89)^{[18]}$.

The mean number of retrieved LN (LN yield) was 20.6 (range 11.3-35.5). The number of total LN removed was significantly influenced by the robotic approach compared to the open one: in the study by Narayan et al. ${ }^{[18]}$, the median LN yield resulted 27 (IQR 19-41) for RARC and 20.5 (IQR 13-28) for ORC ( $P<$ $0.001)$. The difference between female and male cohorts was not statistically significant: mean LN removed 19 (range 12-34)vs. 18 (8-37) in the study by Pruthi et al. ${ }^{[19]}$ and 16 vs. $19(P=0.32)$ in the study by Kang et al. ${ }^{[16]}$.

\section{Postoperative functional outcomes}

Three of the collected studies reported data on recovery of urinary continence and sexual function after RARC in iN female patients. One of these also administered a questionnaire to assess HRQoL ${ }^{[13]}$.

The study by Canda et al. ${ }^{[21]}$, collecting the initial experience of NS-RARC in their institute, described poor functional outcomes in the only two female patients who underwent the procedure (NS-RARC and intracorporeal Studer pouch): at the time of data collection, they both had severe ( $>3$ pads/die) daytime and poor (wet, leakage, and urinary incontinence (UI) during sleep) nighttime UI. However, the postoperative follow-up was very limited for these two patients ( 6 and 5 months).

The study by Tyritzis et al. ${ }^{[22]}$, analyzing the effects of RARC on both male and female patients (all female patients received a NS procedure by preserving the autonomic nerves identified on the anterior vaginal wall at the 10 o'clock and 2 o'clock positions), showed the continence rate for daytime and nighttime at 12 months of follow-up was $74.2 \%$ for men, while two out of three evaluable female patients (66.7\%) were continent ( $\leq 1 \mathrm{pad} / \mathrm{die}$ ) during both daytime and nighttime. No need for a pad was recorded in $27.5 \%$ of 
men $(27.5 \%)$ and one woman (12.5\%). One female patient had to perform CIC (12.5\%). Four of six evaluable women (66.7\%) remained sexually active postoperatively; among men, $26(81.2 \%)$ of the nervespared patients were potent with or without PDE5 medication at 12 months.

Finally, the study by Tuderti et al ${ }^{[13]}$, the most recent study included in our research, aimed to illustrate the results of the SS-RARC technique (with the preservation of utero-vaginal hypogastric plexus) in women receiving iN. In their cohort of patients, daytime and nighttime continence recovery probabilities after one year of follow-up were $90.9 \%$ and $86.4 \%$, respectively. Three patients had to perform CIC twice a day (27.2\%). Concerning the EORTC-QLQ-C30 questionnaire, global health status/QoL and physical and emotional functioning items improved significantly over time (all $P \leq 0.04$ ). According to the EORTCQLQ-BLM30 questionnaire, specific for BCa, urinary symptoms worsened at 3 months with a significant recovery at one year $(P=0.02)$. The Female Sexual Function Index $(F S F I)$ global score and FSFI domains such as arousal, lubrication, orgasm, satisfaction, and pain worsened over the first 3 months with a subsequent improvement at one year (all $P \leq 0.04$ ). Moreover, comparing baseline $v s$. one-year scores, arousal and orgasm domains experienced a complete recovery (both $P=0.10$ ), while lubrication, satisfaction, and pain domains, as well as FSFI global scores, experienced a satisfying improvement but were statistically significantly lower than baseline (all $P \leq 0.025)$. Overall, 8 out of 11 patients $(72.7 \%)$ were sexually active at the 12 -month evaluation.

As supplementary analysis, the authors compared a cohort of standard RARC patients with the SS-RARC cohort. The two cohorts were homogeneous for all baseline, clinical, and pathological features (all $P \geq 0.14$ ) except for age, with SS-patients being significantly younger (47.1 years $v s .61 .7$ years, $P<0.001)$. Perioperative complications and LOS were comparable between the groups $(P=0.25$ and $P=0.67$, respectively). Daytime continence recovery probability was significantly higher in the SS-cohort (one-year rate $90.9 \%$ vs. $74 \%$, log-rank $P=0.02$ ).

\section{DISCUSSION}

The treatment of $\mathrm{BCa}$ in female patients has historically been challenging for specialists, not only because of the possibility of a mismatch among surgical, oncological, and QoL outcomes due to the complexity of the procedure and the patient herself but also because the female gender represents a risk factor for poor surgical and oncological results after $\mathrm{RC}^{[23]}$. Regarding surgical and functional outcomes (urinary function, sexual function, and HRQoL), the literature on RC in female patients, as reported in a recent review by Sadighian et al.$^{[5]}$, is still sparse and poorly defined because of the exclusion of women from most studies, small sample sizes, various surgical techniques, and lack of validated questionnaires and standard definitions. Furthermore, the available evidence in the literature on RARC, particularly in female patients, is still relatively recent and scarce, and the data come mainly from small retrospective series. The robotic approach itself is described as less used in female BCa patients than the open approach in several studies $^{[24-29]}$, although in others the difference was not statistically significant ${ }^{[30-34]}$. It should be noted, however, that numerous articles comparing the use of ICUD vs. ECUD found no significant difference in the use of the two reconstructive approaches according to gender ${ }^{[35-37]}$, with even a prevalence of ICUD in female patients ${ }^{[38]}$.

The reviewed evidence suggests that the mean age of female patients undergoing RARC was 61.12 years. They were generally patients with a normal BMI $\left(24.7 \mathrm{~kg} / \mathrm{m}^{2}\right)$. The median OT was $418 \mathrm{~min}$. From our results, the duration of RARC in women resulted comparable with that in men, while the difference in duration between robotic and open approaches was significant ${ }^{[18]}$. However, ORC was found to be a procedure with a higher risk of IT compared to $\mathrm{RARC}^{[18]}$. Regarding LOS, the median time in our study was 
9.8 days. The difference in LOS compared to RARC in male patients was not significant ${ }^{[16,19]}$, as was the comparison between female RARC and ORC $\mathrm{O}^{[18]}$.

We found that the postoperative complication rate after RARC was barely above $30 \%$, with a high CCS complication rate $(\geq 3)$ of only $12 \%$. A recent review analyzing the evidence and most recent findings on gender-specific differences in $\mathrm{BCa}$ considering treatment and outcomes pointed out that women had a significantly longer LOS, longer OT, higher 90-day mortality, and higher postoperative complication rate ${ }^{[39]}$. The results of our research, which focused on robotic surgery, showed that, thus far, the available evidence on the rate of postoperative complications after RARC is still sparse and influenced by low sample sizes, but it could be seen that this rate appears to overlap with the open approach and does not seem to be influenced by gender ${ }^{[18,19]}$. This evolution could be due to the use of robotic surgery and should be investigated in further prospective and randomized studies comparing genders and surgical approaches.

Data in the literature regarding the association between higher rates of complications/reoperation/readmission after RARC and gender are conflicting. An in-depth critical analysis of complications following RARC and ICUD by Tan et al. ${ }^{[40]}$ found that the male gender was significantly associated with the occurrence of 90-day major complications ( $\mathrm{OR}=6.98,95 \% \mathrm{CI}: 1.45-33.58, P=0.015)$. As the authors pointed out, however, this finding may be skewed by the threefold higher number of male patients. Sharma et al. ${ }^{[26]}$, in their study focusing on the comparison between ORC and RARC in surgical control, found that female sex is not significantly related to an increased risk of 30-day complications in pT3/T4 patients after RC. In the study by Hussein et al. ${ }^{[41]}$, there was no evidence of a statistically significant influence of gender on the risk of reoperation after RARC. Al-Daghmin et al..$^{[42]}$, instead, showed that female gender $(\mathrm{OR}=0.41,95 \% \mathrm{CI}$ : $0.20-0.83, P=0.014)$ and $\mathrm{BMI}(P=0.004)$ were independent predictors of 90-day readmissions in their multivariable analysis. Only two articles collected by our research dealt with readmission rates among women who underwent RARC. These studies showed that, considering the first 90 days after surgery, almost $30 \%$ of patients needed readmission. The difference between the risk of readmission after RC in female patients was not found to be significantly influenced by the surgical approach $^{[18]}$. These findings are consistent with the results shown by two relevant population-based analysis comparing RARC and ORC including male and female patients ${ }^{[24,43]}$, but they differ from what was found in a recent multicenter contemporary retrospective cohort comparative study by Soria et al. ${ }^{[30]}$, in which the readmission rate after RARC was significantly higher than after ORC. The authors attributed this difference to the shortening of the LOS evidenced after RARC.

The main long-term complication that leads to reoperation in female patients who underwent RC is vaginal dehiscence ${ }^{[44]}$. The literature regarding this rare but potentially devastating complication is quite scarce; however, it is important to report the relatively high percentage (7\%) of patients who underwent laparoscopic RC who required emergency surgical reoperation for transvaginal bowel evisceration due to vaginal dehiscence recorded in the study by Kanno et al. ${ }^{[4]}$. The authors, also citing the work by Cronin et al ${ }^{[45]}$, hypothesized an association between higher incidence of vaginal dehiscence and minimally invasive approach, which could be due to overuse of electrocautery during colpotomy or inadequate suturing caused by difficulty in suturing the bottom of the pelvic floor. Considering also the high median age of these patients ( 82 years old), according to the authors, a vagina-preserving approach might be one option for older female patients during RC, if possible. According to Lin et al. ${ }^{[46]}$, the authors of the largest case series documenting vaginal failure after RARC and ICUD, prophylactically addressing potential vaginal prolapse at the time of extirpative surgery is an emerging issue. However, considering the rarity of vaginal failure in RARC, these procedures need to be carefully deliberated. 
We found that the rate of PSMs in women undergoing RARC was only $2.5 \%$, and that of $\mathrm{pN}+$ was $12.72 \%$. Comparing ORC and RARC, no significant difference was found regarding PSMs or $\mathrm{pN}^{\left[{ }^{[18]}\right.}$. The study by Matulewicz et al. ${ }^{[27]}$, instead, showed that female sex was significantly correlated with a higher risk of PSMs $(P=0.001)$, but this difference was significant especially in ORC (male $v s$. Female: $11.8 v s .15 .2)$ compared to RARC (11.0 vs. 10.2); in addition, in the study by Sharma et al. ${ }^{[26]}$, the increased incidence of PSMs in women did not achieve significance on multivariable analysis. An important pathological outcome on which the literature is not consistent is the LN yield: in some studies, this was significantly increased with RARC $^{[18,24,27]}$, while, in others, the LN yield was similar between open and robotic techniques ${ }^{[9,26]}$. Based on the findings in our review, restricting the cohort to women only, the impact of robotic surgery appears significant in the number of LNs removed, although the topic should be further investigated given the paucity of available data ${ }^{[18]}$. Moreover, based on the reviewed studies, gender does not seem to affect LN yield $^{[16,19]}$.

Previous systematic reviews focusing on functional outcomes in female patients undergoing RC have found a preponderance of small retrospective studies with significant heterogeneity on this topic $\mathrm{c}^{[5,12,47-49]}$. The urinary function was the most well-studied outcome with daytime UI, nighttime UI, and self-catheterization rates ranging significantly across studies due to heterogeneity in definitions for continence, inclusion criteria, and lack of questionnaire adoption ${ }^{[13,47]}$. In a systematic review aimed to evaluate female sexual dysfunction post RC, considering it an important predictor of HRQoL, the authors found that the most frequently reported sexual disorders were loss of sexual desire and orgasmic disorders ( $49 \%$ and $39 \%$ respectively); however, they highlighted the lack of use of standardized instruments to adequately assess functional outcomes of RC in women ${ }^{[48]}$.

Research in the field of genital-sparing cystectomy (GSC) techniques to improve functional outcomes after cystectomy is gaining prominence ${ }^{[50]}$. Gross et al.$^{\left[{ }^{[1]}\right]}$ and Wishahi et al ${ }^{[52]}$ recently investigated the impact of GSC and subsequent ONB compared with standard RC in maintaining functional outcomes such as urinary continence in women. The former found superior continence rates for GSC and ONB compared with standard RC, without a negative impact on oncological outcome ${ }^{[51]}$. The latter showed that GSC with ONB led to a minimal incidence of hypercontinence (7.80\%), while standard RC led to a higher incidence $(28.88 \%)^{[52]}$. A recent systematic review of the literature regarding OSC techniques showed that preservation of the genital or pelvic organs, in both men and women, yields better sexual outcomes than standard RC without compromising oncologic outcomes; however, the authors emphasized that none of these techniques could be recommended as superior to standard RC, and that large-scale prospective and multi-institutional studies are needed to identify patients suitable for these techniques ${ }^{[50]}$.

According to our research, the results on functional outcomes inherent to RC in female patients are scarce, and those related specifically to the robotic approach are even more reduced: only three studies collected dealt with this issue, and all of them analyzed the topic on a cohort of patients undergoing NS or SS-RARC and subsequent iN. The achieved results vary widely depending on the follow-up time of the patients. While the study by Canda et al. ${ }^{[21]}$ showed poor outcomes related to continence in the two female patients available with a follow-up of only 5-6 months, the results of Tyritzis et al. ${ }^{[22]}$ already show a recovery of both daytime and nighttime continence in female patients at 6 months (40\%), which was further improved at 12-month follow-up (66.7\%). Even more promising results were achieved in the recent study by Tuderti et al. ${ }^{[13]}$, in which continence reached even higher percentages of female patients ( $90.9 \%$ daytime, $86.4 \%$ nighttime). In our results, hypercontinence and subsequent need for CIC ranged from $12.5 \%$ to $27.2 \%$. These results are consistent with what has been shown by previous systematic reviews on the subject that collected data on patients of both genders ${ }^{[5,47,49]}$. 
The paucity of available data as well as the heterogeneity in outcome definition, measurement, and reporting has hampered the usefulness of the current evidence base on female sexual function after RARC and UD. However, the results shown appear promising with a percentage of sexually active women at the 12-month evaluation ranging from $66.7 \%$ to $72.7 \%{ }^{[13,22]}$. Using FSFI, after an initial worsening of the results over the first 3 months after surgery, it is possible to denote a significant improvement at 12 months of follow-up, even if in comparison with the baseline the results remain significantly reduced. These results support what was already highlighted by Bhatt et al. ${ }^{[53]}$ in their study on a subset of women who underwent RC with neurovascular preservation and ONB. They found that FSFI score could be preserved compared with women who did not undergo NS, who had a significant decline.

As already known from previous studies, significant differences in emotional problems, role functioning, fatigue, and appetite were noted among women undergoing RC compared with controls of the general population $^{[47]}$. One study specifically compared outcomes of men compared with women undergoing RC and ileal conduit and found that men have worse sexual function outcomes than women, whereas women experience a greater burden in postoperative cognitive function and future perspective $\mathrm{e}^{[54]}$. The data available in the literature on the impact of different types of UD on HRQoL show a significant advantage of ileal ONB compared to ileal conduit in terms of $\mathrm{HRQoL}^{[55]}$. Based on the findings of Tuderti et al. ${ }^{[13]}$, using the EORTC-QLQ-C30 questionnaire among female patients who underwent RARC and iN, global health status/QoL and physical and emotional functioning items improved significantly over time (all $P \leq 0.04$ ).

It is important to remember that evidence in the literature for functional outcomes after RARC in female patients is relatively recent and, for the moment, we lack objective measurements and standardized methods of detection of important outcomes such as urinary continence, sexual function, and $\mathrm{QoL}^{[12]}$. The current need is therefore for more in-depth evaluations in randomized controlled trials with prolonged follow-up to identify the most appropriate surgical procedure for the specific patient and improve preoperative counseling.

Our systematic review has some limitations. First, the studies collected were all retrospective and most of them were based on single-center cohorts. Therefore, the results may have been exposed to selection bias or bias due to missing data. Second, the sample size was in many cases extremely low, which may have influenced the results by abnormally increasing their significance. Third, the median follow-up of the collected studies was generally short, which may have affected an accurate description of postoperative long-term complications and a proper characterization of functional recovery; prospective randomized studies with extended follow-up would be useful to determine more accurately post-RARC functional outcomes and long-term surgical outcomes. Fourth, our research was limited to English-language records, which may have affected the choice of eligible items.

\section{Conclusions}

RARC and UD for BCa in female patients is a feasible procedure with surgical outcomes overlapping with those in the male patient population. The comparison between RARC and ORC in the female cohort showed a non-inferiority of the robotic approach in terms of postoperative complications and readmission with the added possibility of reducing EBL and increasing the LN yield even if at the expense of a prolonged OT. Postoperative functional outcomes on continence, sexual function, and QoL are still poorly investigated in the available literature, although results inherent in the NS approach appear promising. More standardized templates for reporting functional outcomes as well as randomized prospective studies to better compare techniques and provide the best counseling are required. 


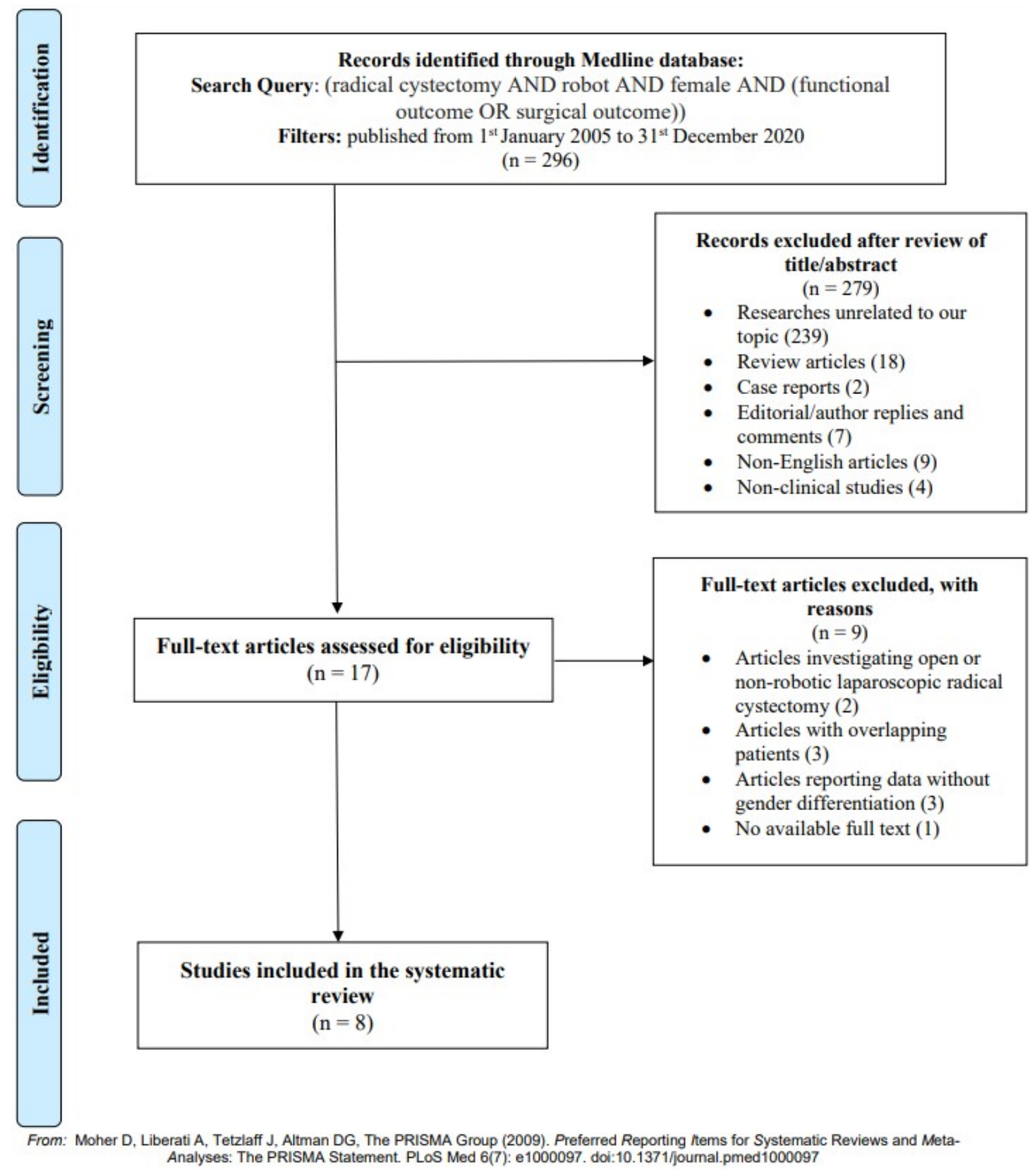

Figure 1. PRISMA flow chart for the article selection process to analyze surgical and functional outcomes in female patients with bladder cancer treated with robot-assisted radical cystectomy (RARC).

\section{DECLARATIONS}

\section{Authors' contributions}

Contributed sufficiently to the scientific work and share collective responsibility and accountability for the results: Ornaghi PI, Tafuri A, Orlando R, Panunzio A, Moschini M, Afferi L, Lonati C, Cerruto MA, Antonelli A 


\section{Availability of data and materials}

Not applicable.

\section{Financial support and sponsorship}

None.

\section{Conflicts of interest}

All authors declared that there are no conflicts of interest.

\section{Ethical approval and consent to participate}

Not applicable.

\section{Consent for publication}

Not applicable.

\section{Copyright}

(C) The Author(s) 2021.

\section{REFERENCES}

1. Siegel RL, Miller KD, Jemal A. Cancer statistics, 2020. CA Cancer J Clin 2020;70:7-30. DOI PubMed

2. EAU Guidelines. EAU annual congress Amsterdam 2020. EAU Guidelines Office, Arnhem, The Netherlands. Available from: http://uroweb.org/guidelines/compilations-of-all-guidelines/ [Last accessed on 30 Jun 2021].

3. Abufaraj M, Foerster B, Schernhammer E, et al. Micropapillary urothelial carcinoma of the bladder: a systematic review and metaanalysis of disease characteristics and treatment outcomes. Eur Urol 2019;75:649-58. DOI PubMed

4. Mungan N, Aben KK, Schoenberg MP, et al. Gender differences in stage-adjusted bladder cancer survival. Urology 2000;55:876-80. DOI PubMed

5. Sadighian M, Porten S. Gender differences in oncologic and functional outcomes in patients with bladder cancer undergoing radical cystectomy with urinary diversion. Curr Opin Urol 2019;29:542-7. DOI PubMed

6. Faba OR, Tyson MD, Artibani W, et al. Update of the ICUD-SIU international consultation on bladder cancer 2018: urinary diversion. World J Urol 2019;37:85-93. DOI PubMed

7. Hussein AA, Elsayed AS, Aldhaam NA, et al. A comparative propensity score-matched analysis of perioperative outcomes of intracorporeal vs extracorporeal urinary diversion after robot-assisted radical cystectomy: results from the International Robotic Cystectomy Consortium. BJU Int 2020;126:265-72. DOI PubMed

8. Cacciamani GE, Rajarubendra N, Artibani W, Gill IS. Robotic intracorporeal urinary diversion: state of the art. Curr Opin Urol 2019;29:293-300. DOI PubMed

9. Bochner BH, Dalbagni G, Marzouk KH, et al. Randomized trial comparing open radical cystectomy and robot-assisted laparoscopic radical cystectomy: oncologic outcomes. Eur Urol 2018;74:465-71. DOI PubMed PMC

10. Parekh DJ, Reis IM, Castle EP, et al. Robot-assisted radical cystectomy versus open radical cystectomy in patients with bladder cancer (RAZOR): an open-label, randomised, phase 3, non-inferiority trial. Lancet 2018;391:2525-36. DOI PubMed

11. Ahmed K, Khan SA, Hayn MH, et al. Analysis of intracorporeal compared with extracorporeal urinary diversion after robot-assisted radical cystectomy: results from the International Robotic Cystectomy Consortium. Eur Urol 2014;65:340-7. DOI PubMed

12. Benamran D, Phé V, Drouin SJ, et al. Functional outcomes obtained with intracorporeal neobladder after robotic radical cystectomy for cancer: a narrative review. J Robot Surg 2020;14:813-20. DOI PubMed

13. Tuderti G, Mastroianni R, Flammia S, et al. Sex-sparing robot-assisted radical cystectomy with intracorporeal padua ileal neobladder in female: surgical technique, perioperative, oncologic and functional outcomes. J Clin Med 2020;9:577. DOI PubMed PMC

14. Liberati A, Altman DG, Tetzlaff J, et al. The PRISMA statement for reporting systematic reviews and meta-analyses of studies that evaluate health care interventions: explanation and elaboration. J Clin Epidemiol 2009;62:e1-34. DOI PubMed

15. Clavien PA, Barkun J, de Oliveira ML, et al. The Clavien-Dindo classification of surgical complications: five-year experience. Ann Surg 2009;250:187-96. DOI PubMed

16. Kang SG, Kang SH, Lee YG, et al. Robot-assisted radical cystectomy and pelvic lymph node dissection: a multi-institutional study from Korea. J Endourol 2010;24:1435-40. DOI PubMed

17. Whittum M, Hussein AA, Ahmed YE, et al. Gynecological organ involvement at robot-assisted radical cystectomy in females: is anterior exenteration necessary? Can Urol Assoc J ;2018:E398-402. DOI PubMed PMC

18. Narayan VM, Seif MA, Lim AH, et al. Radical cystectomy in women: Impact of the robot-assisted versus open approach on surgical outcomes. Urol Oncol 2020;38:247-54. DOI PubMed

19. Pruthi RS, Stefaniak H, Hubbard JS, Wallen EM. Robotic anterior pelvic exenteration for bladder cancer in the female: outcomes and comparisons to their male counterparts. J Laparoendosc Adv Surg Tech A 2009;19:23-7. DOI PubMed 
20. Kaufmann OG, Young JL, Sountoulides P, Kaplan AG, Dash A, Ornstein DK. Robotic radical anterior pelvic exenteration: the UCI experience. Minim Invasive Ther Allied Technol 2011;20:240-6. DOI PubMed

21. Canda AE, Atmaca AF, Altinova S, Akbulut Z, Balbay MD. Robot-assisted nerve-sparing radical cystectomy with bilateral extended pelvic lymph node dissection (PLND) and intracorporeal urinary diversion for bladder cancer: initial experience in 27 cases. BJU Int 2012;110:434-44. DOI PubMed

22. Tyritzis SI, Hosseini A, Collins J, et al. Oncologic, functional, and complications outcomes of robot-assisted radical cystectomy with totally intracorporeal neobladder diversion. Eur Urol 2013;64:734-41. DOI PubMed

23. Uhlig A, Seif Amir Hosseini A, Simon J, et al. Gender specific differences in disease-free, cancer specific and overall survival after radical cystectomy for bladder cancer: a systematic review and meta-analysis. J Urol 2018;200:48-60. DOI PubMed

24. Hanna N, Leow JJ, Sun M, et al. Comparative effectiveness of robot-assisted vs. open radical cystectomy. Urol Oncol 2018;36:88.e19. DOI PubMed

25. Borza T, Jacobs BL, Montgomery JS, et al. No differences in population-based readmissions after open and robotic-assisted radical cystectomy: implications for post-discharge care. Urology 2017;104:77-83. DOI PubMed PMC

26. Sharma P, Zargar-Shoshtari K, Poch MA, et al. Surgical control and margin status after robotic and open cystectomy in high-risk cases: caution or equivalence? World J Urol 2017;35:657-63. DOI PubMed

27. Matulewicz RS, DeLancey JO, Manjunath A, Tse J, Kundu SD, Meeks JJ. National comparison of oncologic quality indicators between open and robotic-assisted radical cystectomy. Urol Oncol 2016;34:431.e9-431.e15. DOI PubMed

28. Hu JC, Chughtai B, O'Malley P, et al. Perioperative outcomes, health care costs, and survival after robotic-assisted versus open radical cystectomy: a national comparative effectiveness study. Eur Urol 2016;70:195-202. DOI PubMed

29. Yu HY, Hevelone ND, Lipsitz SR, et al. Comparative analysis of outcomes and costs following open radical cystectomy versus robotassisted laparoscopic radical cystectomy: results from the US Nationwide Inpatient Sample. Eur Urol 2012;61:1239-44. DOI PubMed

30. Soria F, Moschini M, D'andrea D, et al. Comparative effectiveness in perioperative outcomes of robotic versus open radical cystectomy: results from a multicenter contemporary retrospective cohort study. Eur Urol Focus 2020;6:1233-9. DOI PubMed

31. Cusano A, Haddock P Jr, Jackson M, Staff I, Wagner J, Meraney A. A comparison of preliminary oncologic outcome and postoperative complications between patients undergoing either open or robotic radical cystectomy. Int Braz J Urol 2016;42:663-70. DOI PubMed PMC

32. Bak DJ, Lee YJ, Woo MJ, et al. Complications and oncologic outcomes following robot-assisted radical cystectomy: what is the real benefit? Investig Clin Urol 2016;57:260-7. DOI PubMed PMC

33. Gandaglia G, Karl A, Novara G, et al. Perioperative and oncologic outcomes of robot-assisted vs. open radical cystectomy in bladder cancer patients: a comparison of two high-volume referral centers. Eur J Surg Oncol 2016;42:1736-43. DOI PubMed

34. Tan WS, Sridhar A, Ellis G, et al. Analysis of open and intracorporeal robotic assisted radical cystectomy shows no significant difference in recurrence patterns and oncological outcomes. Urol Oncol 2016;34:257.e1-9. DOI PubMed

35. Wang MS, He QB, Yang FY, Ping H, Xing NZ. A retrospective study comparing surgical and early oncological outcomes between intracorporeal and extracorporeal ileal conduit after laparoscopic radical cystectomy from a single center. Chin Med J (Engl) 2018;131:784-9. DOI PubMed PMC

36. Pyun JH, Kim HK, Cho S, et al. Robot-assisted radical cystectomy with total intracorporeal urinary diversion: comparative analysis with extracorporeal urinary diversion. J Laparoendosc Adv Surg Tech A 2016;26:349-55. DOI PubMed

37. Guru K, Seixas-Mikelus SA, Hussain A, et al. Robot-assisted intracorporeal ileal conduit: marionette technique and initial experience at Roswell park cancer institute. Urology 2010;76:866-71. DOI PubMed

38. Lenfant L, Verhoest G, Campi R, et al. Perioperative outcomes and complications of intracorporeal vs extracorporeal urinary diversion after robot-assisted radical cystectomy for bladder cancer: a real-life, multi-institutional french study. World J Urol 2018;36:1711-8. DOI PubMed

39. Mancini M, Righetto M, Baggio G. Spotlight on gender-specific disparities in bladder cancer. Urologia 2020;87:103-14. DOI PubMed

40. Tan WS, Lamb BW, Tan MY, et al. In-depth critical analysis of complications following robot-assisted radical cystectomy with intracorporeal urinary diversion. Eur Urol Focus 2017;3:273-9. DOI PubMed

41. Hussein AA, Hashmi Z, Dibaj S, et al. Reoperations following robot-assisted radical cystectomy: a decade of experience. J Urol 2016;195:1368-76. DOI PubMed

42. Al-Daghmin A, Aboumohamed A, Din R, et al. Readmission after robot-assisted radical cystectomy: outcomes and predictors at 90day follow-up. Urology 2014;83:350-6. DOI PubMed PMC

43. Leow JJ, Reese SW, Jiang W, et al. Propensity-matched comparison of morbidity and costs of open and robot-assisted radical cystectomies: a contemporary population-based analysis in the United States. Eur Urol 2014;66:569-76. DOI PubMed

44. Kanno T, Ito K, Sawada A, et al. Complications and reoperations after laparoscopic radical cystectomy in a Japanese multicenter cohort. Int J Urol 2019;26:493-8. DOI PubMed

45. Cronin B, Sung VW, Matteson KA. Vaginal cuff dehiscence: risk factors and management. Am J Obstet Gynecol 2012;206:284-8. DOI PubMed PMC

46. Lin FC, Medendorp A, Van Kuiken M, Mills SA, Tarnay CM. Vaginal dehiscence and evisceration after robotic-assisted radical cystectomy: a case series and review of the literature. Urology 2019;134:90-6. DOI PubMed

47. Smith AB, Crowell K, Woods ME, et al. Functional outcomes following radical cystectomy in women with bladder cancer: a systematic review. Eur Urol Focus 2017;3:136-43. DOI PubMed

48. Zahran MH, Fahmy O, El-Hefnawy AS, Ali-El-Dein B. Female sexual dysfunction post radical cystectomy and urinary diversion. 
Climacteric 2016;19:546-50. DOI PubMed

49. Veskimäe E, Neuzillet Y, Rouanne M, et al. Systematic review of the oncological and functional outcomes of pelvic organ-preserving radical cystectomy $(\mathrm{RC})$ compared with standard $\mathrm{RC}$ in women who undergo curative surgery and orthotopic neobladder substitution for bladder cancer. BJU Int 2017;120:12-24. DOI PubMed

50. Quesada-Olarte J, Álvarez-Maestro M, Gómez-Rivas J, Toribio-Vázquez C, Aguilera Bazán A, Martínez-Piñeiro L. Organ-sparing cystectomy techniques: functional and oncological outcomes, review and current recommendations. Arch Esp Urol 2020;73:961-70. PubMed

51. Gross T, Furrer M, Schorno P, et al. Reproductive organ-sparing cystectomy significantly improves continence in women after orthotopic bladder substitution without affecting oncological outcome. BJU Int 2018;122:227-35. DOI PubMed

52. Wishahi M, Ismail MA, Elganzoury H, et al. Genital-sparing cystectomy versus standard urethral-sparing cystectomy followed with orthotopic neobladder in women with bladder cancer: incidence and causes of hypercontinence with an ultrastructure study of urethral smooth muscles. Open Access Maced J Med Sci 2019;7:978-81. DOI PubMed PMC

53. Bhatt A, Nandipati K, Dhar N, et al. Neurovascular preservation in orthotopic cystectomy: impact on female sexual function. Urology 2006;67:742-5. DOI PubMed

54. Siracusano S, D'Elia C, Cerruto MA, et al. Quality of life in patients with bladder cancer undergoing ileal conduit: a comparison of women versus men. In Vivo 2018;32:139-43. DOI PubMed PMC

55. Cerruto MA, D'Elia C, Siracusano S, et al. Systematic review and meta-analysis of non RCT's on health related quality of life after radical cystectomy using validated questionnaires: Better results with orthotopic neobladder versus ileal conduit. Eur J Surg Oncol 2016;42:343-60. DOI PubMed 